\title{
Evaluation of antipsoriatic activity of gel containing Pongamia pinnata extract on Imiquimod-induced psoriasis
}

\author{
Kamlesh Wadher ${ }^{*}$ (D), Shital Dabre, Anjali Gaidhane, Sagar Trivedi and Milind Umekar
}

\begin{abstract}
Background: Pongamia pinnata (Fabaceae) is among those categories of plants mentioned in Ayurveda and traditionally known to use in several types of disease and disorders. The objective of the present work was to investigate the anti-psoriatic activity of Pongamia pinnata leaves extracts in Herbal gel formulation.

Results: Hydroalcoholic leaves extract of Pongamia pinnata was first subjected to phytochemical screening and quantification of phytoconstituents. Herbal gel was prepared containing Pongamia pinnata extracts using Carbopol 934 as gelling agent. The prepared gel formulations were studied for $\mathrm{pH}$, viscosity, Spreadability and in vitro diffusion studies. The imiquimod-induced psoriatic mouse model, showed a prominent anti-psoriatic activity of the extract as evident through index grading. Treatment with extract confirmed a noteworthy reduction in psoriasis in the treated groups as there was a considerable diminution in the thickness and scaling of skin.

Conclusions: Lack of proper treatment and disadvantages associated with allopathic medicines pave the way to extensive research in natural products with anti-psoriatic activity. The present research scientifically justified the antipsoriatic activity of the Hydroalcoholic extracts of Pongamia pinnata leaves.
\end{abstract}

Keywords: Pongamia pinnata, Anti-psoriatic activity, Imiquimod, Medicinal plant

\section{Background}

Psoriasis is a hyper proliferative neutrophilic skin disorder affecting around 5-6\% of the world population, with prevalence rate in adult from $0.5 \%-11.4 \%$ [23]. The pathogenesis of psoriasis is associated with increased production of inflammatory cytokines that cause hyperkeratosis $[13,19]$. Psoriasis is a multifactorial with numerous key factors such as, genetic vulnerability, environmental triggers, skin barrier distruption and immune dysfunction [18]. On the basis of extent of inflammation, localization of rash and severity, psoriasis can be categorized as, Vulgaris (plaque), guttate, inverse, pustular and erythrodermic $[6,15]$. Vulgaris (plaque) has reported to affects around $85 \%-90 \%$ of psoriatic patients affecting physically and mentally a lot $[7,12]$.

* Correspondence: kamleshwadher@gmail.com

Department of Pharmaceutics, Smt. Kishoritai Bhoyar College of Pharmacy, Kamptee, Nagpur 441002, India

\section{Springer Open}

Traditional medicines are gaining importance on account of the associated side effects of synthetic medicines [25]. Pongamia is a genus having one species only Pongamia pinnata (Linn.) [Syn. Pongamia glabra (Vent); Derris indica (Lamk.)] which belongs to family Fabaceae and subfamily Papilionaceae is native in tropical and temperature regions of Asia. It is among that category of plants which has wide applicability in the treatment of diseases such as for treatment of piles, ulcers, skin diseases, and wounds and rheumatic joints [20]. Most scientist and researchers have worked on various extracts and chemical constituents, and reported the antioxidant, antimicrobial, antiparasite, anti-inflammatory, anti-convulsant, anti-diabetic, antihyperammnonemic, cytotoxicity, anthelminthic, insecticidal and immunomodulatory activities [1].

(c) The Author(s). 2021 Open Access This article is licensed under a Creative Commons Attribution 4.0 International License, which permits use, sharing, adaptation, distribution and reproduction in any medium or format, as long as you give appropriate credit to the original author(s) and the source, provide a link to the Creative Commons licence, and indicate if changes were made. The images or other third party material in this article are included in the article's Creative Commons licence, unless indicated otherwise in a credit line to the material. If material is not included in the article's Creative Commons licence and your intended use is not permitted by statutory regulation or exceeds the permitted use, you will need to obtain permission directly from the copyright holder. To view a copy of this licence, visit http://creativecommons.org/licenses/by/4.0/. 


\section{Materials and methods}

Imiquimod was obtained from Glenmark Pharmaceutical, Mumbai, India. Carbopol 934 was procured from Loba chemie LTD, Mumbai. All other chemicals used were of analytical grade.

\section{Plant material and extraction}

The leaves of Pongamia pinnata were procured from the local herbal habitat of Nagpur region, Maharashtra, India and were authenticated from Department of Botany, Rashtrasant Tukadoji Maharaj Nagpur University, Nagpur, Maharashtra, India (voucher specimen No.: 1017). The collected stems of the plant $(500 \mathrm{~g})$ were shade dried, coarsely powdered and macerated with water and ethanol (7:3). After 7 days the solvent was filtered and subsequently concentration to dryness at a room temperature to obtained extract. The extract (yield: $5.98 \% \mathrm{w} / \mathrm{w}$ ) was then kept in a desiccator until use.

\section{Phytochemical standardization}

Preliminary phytochemical screening of the hydroalcohlic extract of Pongamia pinnata (EPP) for the presence of various phytoconstituents such as, alkaloids, phenolic compounds, flavonoids, tannins, terpenoids and diterpenoids were carried out as per standards procedure [3]. Total alkaloid content was estimated as per the usual gravimetric analysis [5] while anthrone reagent was used to determine the total carbohydrate content in EPP [22]. Total phenolic and tannin content in EPP was estimated according to the reported method [24] using Folin- ciocalteau reagent. Total flavonoid and saponin content were estimated by the reported methods $[8,10]$.

Formulation and characterization of Pongamia pinnata gel Accurately weighed quantity of gelling agent Carbopol 934 was dispersed in distilled water under constant stirring of $800 \mathrm{rpm}$ for $30 \mathrm{~min}$ at temperature of $37^{\circ} \mathrm{C}$ until a gel like mass was observed. After reaching the gel like consistency required amount of Methyl parabens were dissolved in propylene glycol whereas EPP $(0.5 \mathrm{~g})$ was dissolved in ethanol, and both solutions were mixed with the aqueous phase with continuous stirring until a homogenous gel was formed. The gel was further rendered alkaline using 1to 2 drops of Triethanolamine (TEA) and subsequently $0.5 \mathrm{ml}$ of glycerin was added as a humectant.

Various pharmaceutical parameters of the formulated gel were evaluated which included, physical appearance, $\mathrm{pH}$, viscosity, Spreadability [11] in vitro diffusion studies. The skin biocompatibility of the gel was done by measuring $\mathrm{pH}$ using digital $\mathrm{pH}$ meter (ELICO) at room temperature and a Brookfield viscometer to determine the Viscosity of the gel [2]. The spreadability of the Pongamia pinnata gel was determined using glass slides
$(7.5 \times 2.5 \mathrm{~cm})$, where gel $(1 \mathrm{~g})$ was applied within the two slides, which was retained for $1 \mathrm{~min}$. Spreadability of the formulation indicates the ability of the formulation to eject from tube in uniform way and desired quantity when squeezed.

$$
\mathrm{S}=\mathrm{M} \cdot \mathrm{L} / \mathrm{T}
$$

Where, $\mathrm{S}=$ spreadability, $\mathrm{M}=$ weight tied to upper slide, $\mathrm{L}=$ length of glass slides, $\mathrm{T}=$ time taken to separate the slides completely from each other.

\section{In vitro release study}

The in vitro drug release profile of the PPE gel was determined by dispersing $1 \mathrm{~g}$ of the gel in $25 \mathrm{~mL}$ of phosphate buffer saline (PBS, $\mathrm{pH} 7.4$ ), placed in the dialysis bag (cutoff $14 \mathrm{kDa}$ ) with continuous stirring on a magnetic stirrer at $100 \mathrm{rpm}$ at $37 \pm 1^{\circ} \mathrm{C}$. One $\mathrm{mL}$ of the dispersion was withdrawn from the medium and replaced with the same amount of medium at a definite time interval and drug release was analyzed at $210 \mathrm{~nm}$ (Shimadzu-1700 UV visible spectrophotometer). The experiments were carried out in triplicate.

\section{Drug content}

The drug content of PPE gel was determined by dissolving an accurately weighed quantity of formulation in about $50 \mathrm{~mL}$ of $\mathrm{pH} 6.8$ phosphate buffer, from the resulting solution $5 \mathrm{ml}$ of solution was pipetted and was diluted to $25 \mathrm{ml}$. The subsequent was filtered and absorbance was measured at $210 \mathrm{~nm}$ using Shimadzu1700 UV visible spectrophotometer [4].

\section{Ex-vivo permeation study}

Skin permeation study was performed on dorsal skin of the rats by means of modified Franz diffusion cell following same method as described in the in- vitro drug release study of gel. The skin was judiciously checked through an amplifying glass to make sure that the test was free from any surface inconsistency like tiny gaps or hole [21].

\section{Acute skin irritation test for gel}

PPE gel was checked for acute skin irritation as per standard protocol. Dorsal side of rat. A $500 \mathrm{~mm}^{2}$ area of dorsal hair of mice were shaved and cleaned. $5 \% \mathrm{w} / \mathrm{w}$ of gel formulation was applied to three different groups of animals and fourth group was kept control. The skin of animal was then checked for erythema, inflammatory reactions and edema after $4 \mathrm{~h}$ and for $48 \mathrm{~h}$ of application of topical gel preparation. 


\section{Anti-psoriatic activity}

\section{Imiquimod-induced psoriatic mouse model}

As per the guidelines of the Committee for the Purpose of Control and Supervision of Experiments on Animals (CPCSEA, Government of India) all experiments were carried out with Reference no- 853/IAEC/17-18/23. And all the study protocols were approved by the Animal Ethical Committee of the Central Animal Facility, Smt. Kishoritai Bhoyar college of pharmacy, Kamptee, Nagpur, India.

Rats were procured from National institute of Nutrition, Hyderabad, India. Rats of 8-11 weeks old were used in the study. In each experimental group (disease free/ control/disease), animals were smoothly and clean shaven along their back part. Psoriasis in mouse was induced using imiquimod-induced psoriasis, the animal's dorsal part was shaved and commercially available 5\% (IMQ) cream (Aldara; $3 \mathrm{M}$ Pharmaceuticals) with dose of $62.5 \mathrm{mg}$ of imiquimod was topically applied for 7 consecutive days and translating in a daily dose of $3.125 \mathrm{mg}$ of the active compound. Control rat were treated similarly with a control vehicle cream. After 7 days skin biopsies were taken immediately, fixed in $10 \%$ formalin and embed in paraffin. The tissue section ( $4 \mu \mathrm{m}$ thick) was taken and stained with haematoxylin and eosin. The number of keratinocytes layers including the basal layer was counted by direct microscopy (Nikon Trinocular Microscope, Model E-200) [9, 16].

\section{Scoring severity of skin inflammation}

Antipsoriatic activity of the PPE herbal gel was evaluated on the basis of PASI (Zero, Slight, Moderate, Very marked) score along with the histopathology of skin [17].

\section{Statistical analysis}

The experimental results are expressed as mean \pm SEM, with six animals in each group followed by one-way analysis of variance (ANOVA). Newman-keuls test for multiple comparisons was applied for determining the statistical significance between different groups. All the statistical analysis were performed using, Graph Pad Prism software. $P$ values $<0.05$ were considered to be significant.

\section{Results}

\section{Phytochemical standardization}

Preliminary phytochemical analysis of the EPP revealed the presence of mainly alkaloids, carbohydrate, flavonoid, saponins, amino acid as a major component.

\section{Evaluations of formulated gel}

The gel was evaluated for physical appearance and it was found to be uniform, creamy white, homogenous and

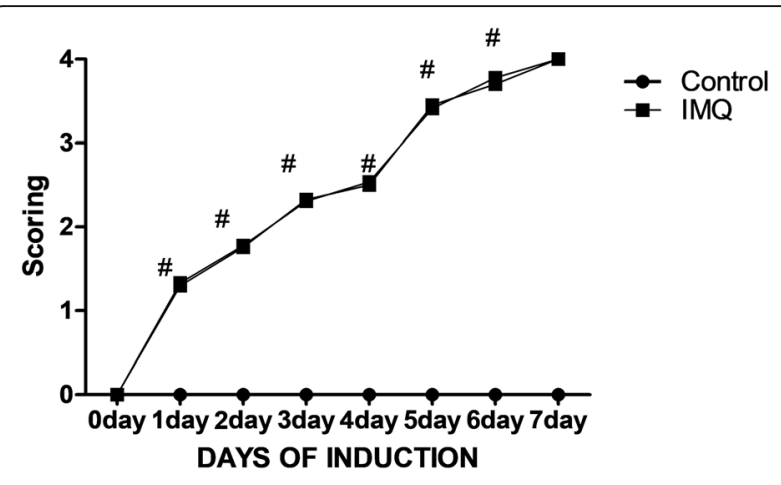

Fig. 1 Psoriasis Induced Graph

non-sticky. The $\mathrm{pH}$ of prepared gel with extract was found to be 6.5 which is suitable for topical application. The viscosity of the gel was found to be $2100 \mathrm{cps}$ to $1400 \mathrm{cps}$ at $1 \mathrm{rpm}$ to $20 \mathrm{rpm}$. The spreadability was found to be $9.6 \pm 0.53 \mathrm{~g} / \mathrm{sec}$. The drug content was found to be uniform throughout the formulated gel with the range are $92.32 \% \pm 0.43$ and average value is assuring the process adopted to prepare the gel is capable of giving reproducible results. From the data of \% drug diffusion, we observed that, the prepared topical gel formulation with PP extract released a maximum of $59.11 \% \pm 0.512 \%$ of extract over a period of $6 \mathrm{~h}$ which shows that the gel formulation can control the release of drug for a longer period of time.

The formulation of gel shows $67.270 \% \pm 0.304$ of drug permeated in $6 \mathrm{~h}$. The gel was subjected to accelerated stability testing as per $\mathrm{ICH}$ guidelines. The gel was stored at a temperature of $40 \pm 2{ }^{\circ} \mathrm{C}$ and $75 \pm 5 \% \mathrm{RH}$ for 90 days ( 3 months). The results showed no significant changes in physical appearance, viscosity, spreadability, and drug content.

\section{Antipsoriasis activity Imiquimod-induced psoriasis mouse model}

Imiquimod-induced psoriasis mouse model was used to induce psoriasis in rat within period of 7 days. The grading was given to each rat before and after treatment with test, and psoriatic control along with naive control [14].

Table 1 PASI grading of psoriasis animal before and after treatment

\begin{tabular}{lll}
\hline Subject No. & $\begin{array}{l}\text { Initial grading after } \\
\text { induction of psoriasis } \\
\text { using Imiquimod } \\
\text { (PASI) }\end{array}$ & $\begin{array}{l}\text { Final grading } \\
\text { after treatment } \\
\text { of } 7 \text { days } \\
\text { (PASI) }\end{array}$ \\
\hline 1.Navie Control & None & None \\
2. Treatment of drug & Very Marked & None \\
3.Marketed formulation & Very Marked & None \\
\hline
\end{tabular}




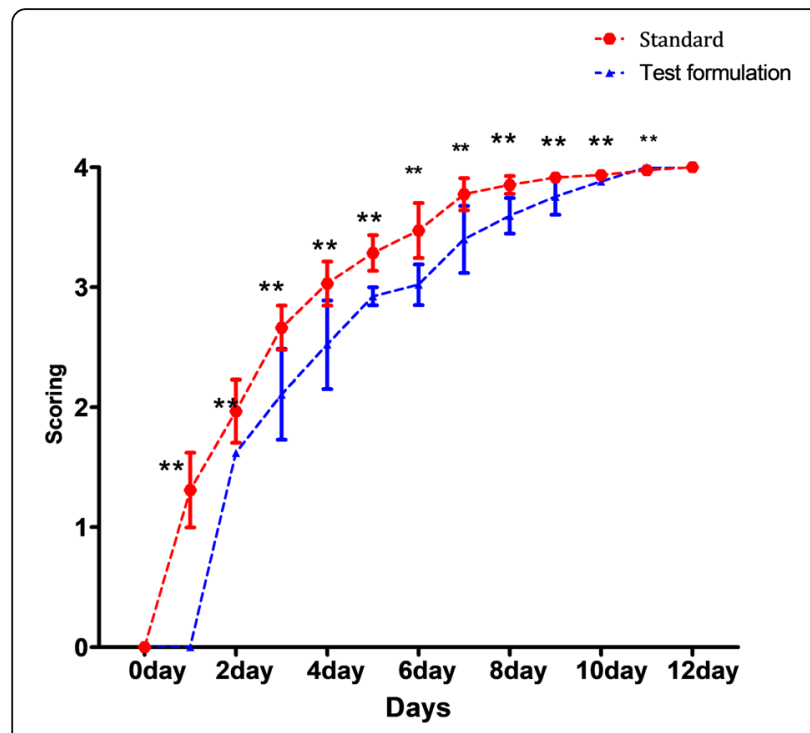

Fig. 2 Effect of extract on psoriasis score in rats. Each point indicates psoriasis score. ${ }^{* *} P<0.0001, \# P<0.0001$ vs. STD treated rats

Figure 1 represents the effect of topical treatment of EPP on PASI grading on IQM-induced psoriatic mice (Table 1).

As shown in Fig. 1, two-way ANNOVA followed by post hoc Bonferroni multiple comparison test reveals that, there was significant increase in psoriasis after applying (topically) imiquimod, (erythema and scaling) day by day $(\# p<0.0001 \mathrm{IMQ}$ induced animal) $[\mathrm{F}=$ 5166.14].

Daily treatment with extract (Combination with PEG topical) starting from post day-8 following IMQ, progressively reduced the psoriasis score in rats as compared to the standard tested animals as shown in Figs. 2 and 3. Application of two-way ANOVA showed the significant interaction $[\mathrm{F}(4.26,26), P<0.05]$ between test treatment and STD [F(49.33), $P<0.001]]$. Application of post hoc Bonferroni multiple comparison test revealed significant recovery of adjuvant psoriasis on postpsoriasis days $12(P<0.001)$ of the protocol.

The histopathological examination (Fig. 4) showed intact fibroblast and collagen tissue in treated test in comparison with control groups where deterioration and necrosis were observed.

\section{Discussion}

The prepared gel was evaluated for its $\mathrm{pH}$, spreadability, drug content and \% drug diffusion. All parameters were found to be satisfactory is capable of giving reproducible results. The data of \% drug diffusion clearly indicated that, the gel formulation can control the release of drug for a longer period of time. Various kinetic models viz., zero order, first order, Higuchi, Matrix and KorsmeyerPeppas model were explored to determine the model-fit


Fig. 3 Photographic images of the study a: Naive Control, b: Psoriasis Induced, c: Test Formulation 

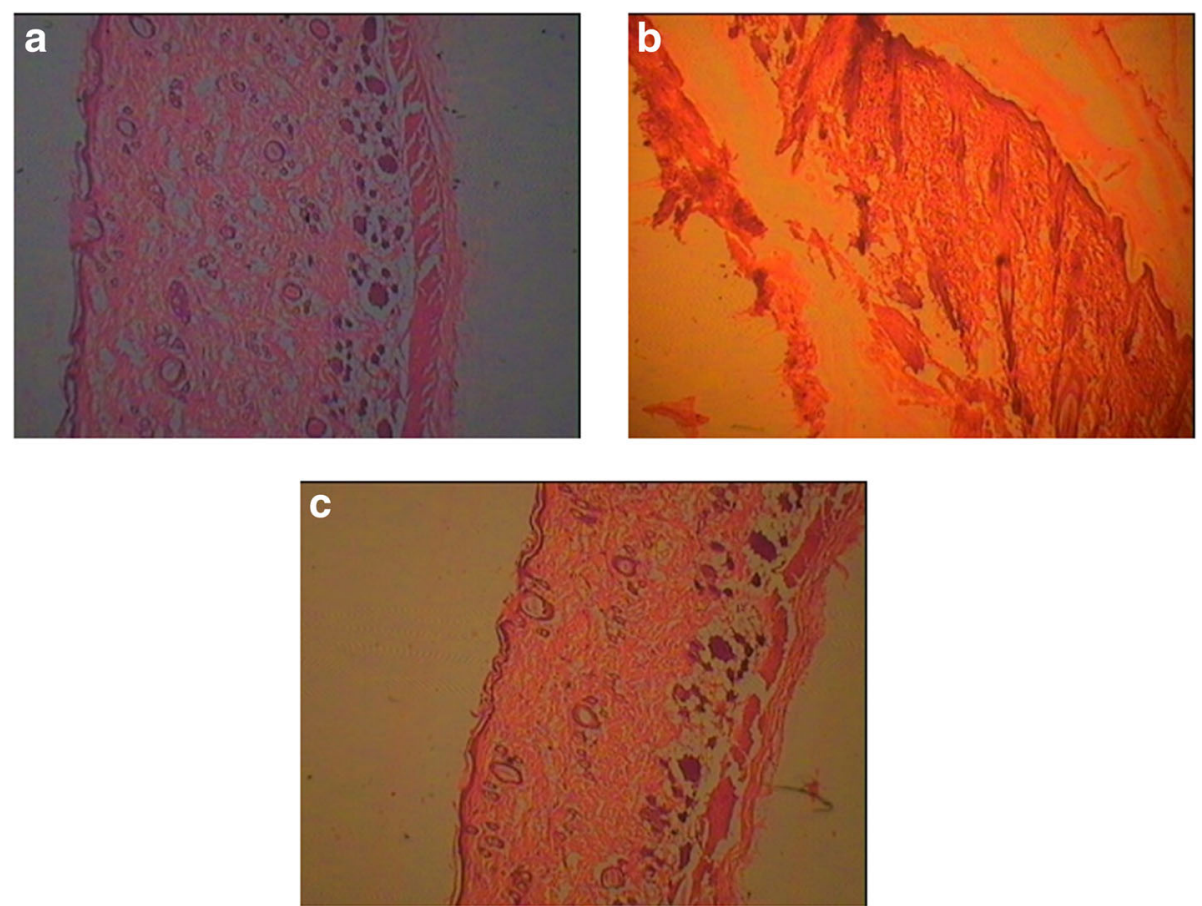

Fig. 4 Histopathology of Normal, Psoriasis and Test treated test (a: Naïve Control, b: Psoriasis Induced, c: Test Treated)

of the release profile of gel. Based on the obtained value of the regression coefficient $(\mathrm{R} 2=0.9985)$, first order model was found to be the best representative model describing the diffusion of gel. Additionally, the release exponent value (n) was estimated to be 0.7533 , thus indicating a non-Fickian Diffusion release. Ex vivo permeation profiles of extract follow zero-order kinetics model $\left(R^{2}=0.9985\right)$. The release exponent value (n) was estimated to be 0.6517 , thus indicating a non-Fickian super case II Diffusion release. Thus, gel was found to significantly enhance both the rate and the extent of drug Permeation through rat Skin. Stability study results indicated that there were no any significant changes in physical appearance, \% viscosity, \% spreadability, and drug content and thus confirms the stability of gel.

Imiquimod-induced psoriasis mouse model was used to induce psoriasis in rat. Application of IQM drug for seven successive days to the mice showed development of erythema, scaling and thickening of the skin. Treatment with EPP confirmed a marked recovery from psoriasis in the treated groups as there was a considerable diminution in the thickness and scaling of skin, which was also confirmed through reduced grading of the PASI scale of treated groups. The result of histopathology clearly shows that, on treatment with EPP topically, regeneration in the tissue integrity was observed with greater collagen content, angiogenesis, keratinization, fibroblast proliferation as compared to control groups.

\section{Conclusion}

Lack of feasible treatment and disadvantages associated with allopathic medicines to cure psoriasis has led to extensive research in herbal products with anti -psoriatic activity. Literature survey revealed that Pongamia pinnata was used for the treatment of psoriasis by traditional therapist. The present research scientifically justified the anti-psoriatic activity of the Hydroalcoholic extracts of Pongamia pinnata leaves.

\section{Abbreviations}

EPP/PPE: Extract of Pongamia pinnata; IMQ: Imiquimod; PASI: Psoriasis Area and Severity Index; ANOVA: One-way analysis of variance

\section{Acknowledgements}

The authors express their gratitude to Smt. Kishoritai Bhoyar College of Pharmacy, Kamptee Nagpur, Maharashtra, India for carrying out this project.

\section{Authors' contributions}

The research was carried out in collaborations of all the authors. As a Corresponding author I assured that all authors have read and approved the manuscript.

Ethics approval and consent to participate

All experiments were carried out as per the guidelines of the Committee for the Purpose of Control and Supervision of Experiments on Animals (CPCSEA, Ministry of Environment and Forest, Government of India). Reference no853/IAEC/17-18/23. All the study protocols were approved by the Animal Ethical Committee of the Central Animal Facility, Smt. Kishoritai Bhoyar college of pharmacy, Kamptee, Nagpur, India.

Consent for publication

We declare that the manuscript is original and has not been published before in any other journal. 


\section{Competing interests}

The authors declare no conflict of interest, financial or otherwise.

Received: 16 November 2020 Accepted: 2 February 2021

Published online: 09 February 2021

\section{References}

1. Al Muqarrabun LM, Ahmat N, Ruzaina SA, Ismail NH, Sahidin I. Medicinal uses, phytochemistry and pharmacology of Pongamia pinnata (L.) Pierre: a review. J Ethnopharmacol. 2013;150(2):395-420. https://doi.org/10.1016/j. jep.2013.08.041.

2. Baccou JC, Lambert F, Sauvaire Y. Spectrophotometric method for the determination of total steroidal sapogenin. Analyst. 1977;102(1215):458-65. https://doi.org/10.1039/an9770200458.

3. Bajpai VK, Rahman A, Shukla S, Mehta A, Shukla S, Yasir Arafat SM, et al. Antibacterial activity of leaf extracts of Pongamia pinnata from India. Pharm Biol. 2009:47:1162-7. https://doi.org/10.3109/13880200903019218.

4. Bonacucina G, Cespi M, Characterization PGF. Stability of emulsion gels based on acrylamide/sodium Acryloyldimethyl Taurate copolymer. AAPS PharmSciTech. 2009;10:368-75. https://doi.org/10.1208/s12249-009-9218-1.

5. Evans E. Trease and Evans, pharmacognosy. 15th ed. Edinburgh: WB Saunders; 2002.

6. Galimova ES, Akhmetova VL, Khusnutdinova EK. Molecular genetic basis of predisposition to psoriasis. Genetika. 2008;44(5):594-605Russian. https://doi. org/10.1134/s1022795408050025.

7. Griffiths $C E$, Barker JN. Pathogenesis and clinical features of psoriasis. Lancet. 2007;370(9583):263-71. https://doi.org/10.1016/S0140-6736(07)61128-3.

8. Hagerman AE, Riedl KM, Jones GA, Sovik KN, Ritchard NT, Hartzfeld PW, et al. High molecular weight plant Polyphenolics (tannins) as biological antioxidants. J Agric Food Chem. 1998;46:1887-92. https://doi.org/10.1021/ jf970975b.

9. Khullar R, Kumar D, Seth N, Saini S. Formulation and evaluation of mefenamic acid emulgel for topical delivery. Saudi Pharm J. 2012;20(1):63-7. https://doi.org/10.1016/j.jsps.2011.08.001.

10. Kumaran A, Karunakaran R. In vitro antioxidant activities of methanol extracts of five Phyllanthus species from India. LWT Food Sci Technol. 2007; 40(2):344-52. https://doi.org/10.1016/.I.lwt.2005.09.011.

11. Laxmi RJ, Karthikeyan R, Babu PS, Babu RV. Formulation and evaluation of antipsoriatic gel using natural excipients. J Acute Dis. 2013;2:115-21. https:// doi.org/10.1016/s2221-6189(13)60110-9.

12. Lowes MA, Bowcock AM, Krueger JG. Pathogenesis and therapy of psoriasis. Nature. 2007;445(7130):866-73. https://doi.org/10.1038/nature05663.

13. Lowes MA, Suárez-Fariñas M, Krueger JG. Immunology of psoriasis. Annu Rev Immunol. 2014;32:227-55. https://doi.org/10.1146/annurev-immunol-032 713-120225

14. Luo DQ, Wu HH, Zhao YK, Liu JGH, Wang F. Original research: different imiquimod creams resulting in differential effects for imiquimod-induced psoriatic mouse models. Exp Biol Med. 2016;241:1733-8. https://doi.org/1 $0.1177 / 1535370216647183$

15. Ayala-Fontánez N, Soler DC, McCormick TS. Current knowledge on psoriasis and autoimmune diseases. Psoriasis (Auckl).2016;22(6):7-32. https://doi.org/1 $0.2147 /$ PTT.S64950.

16. Mutimer MN, Riffkin C, Hill JA, Glickman ME, Cry GN. Modern ointment base technology. II. Comparative evaluation of bases. J Am Pharm Assoc Am Pharm Assoc. 1956;45(4):212-8. https://doi.org/10.1002/jps.3030450406.

17. Mysliwietz J, Thierfelder S. Antilymphocytic antibodies and marrow transplantation. XII. Suppression of graft-versus-host disease by T-cellmodulating and depleting antimouse CD3 antibody is most effective when preinjected in the marrow recipient. Blood. 1992;80(10):2661-7.

18. Raychaudhuri SK, Maverakis E, Raychaudhuri SP. Diagnosis and classification of psoriasis. Autoimmun Rev. 2014;13(4-5):490-5. https://doi.org/10.1016/j.a utrev.2014.01.008.

19. Rendon A, Schäkel K. Psoriasis pathogenesis and treatment. Int J Mol Sci. 2019;20(6):1475. https://doi.org/10.3390/ijms20061475.

20. Sajid ZI, Anwar F, Shabir G, Rasul G, Alkharfy KM, Gilani AH. Antioxidant, antimicrobial properties and phenolics of different solvent extracts from bark, leaves and seeds of Pongamia pinnata (L.) Pierre. Molecules. 2012; 17(4):3917-32. https://doi.org/10.3390/molecules17043917.

21. Stanos SP. Topical agents for the management of musculoskeletal pain. J Pain Symptom Manag. 2007;33(3):342-55. https://doi.org/10.1016/j.jpa insymman.2006.11.005.
22. Wagner $\mathrm{H}$, Bladt $\mathrm{S}$. Plant drug analysis: a thin layer chromatography atlas. 2nd ed. Berlin: Springer-Verlag; 1996. https://doi.org/10.1007/978-3642-00574-9.

23. Wollina U, França K, Lotti T, Tirant M. Adjuvant treatment of chronic plaque psoriasis in adults by a herbal combination: open German trial and review of the literature. Dermatol Ther. 2020;33(4):e12624. https://doi.org/10.1111/ dth. 12624.

24. Yemm EW, Willis AJ. The estimation of carbohydrates in plant extracts by anthrone. Biochem J. 1954;57(3):508-14. https://doi.org/10.1042/bj0570508.

25. Yuan $\mathrm{H}, \mathrm{Ma} \mathrm{Q}$, Ye L, Piao G. The traditional medicine and modern medicine from natural products. Molecules. 2016;21(5):559. https://doi.org/10.3390/ molecules21050559.

\section{Publisher's Note}

Springer Nature remains neutral with regard to jurisdictional claims in published maps and institutional affiliations.

\section{Submit your manuscript to a SpringerOpen ${ }^{\circ}$ journal and benefit from:}

- Convenient online submission

- Rigorous peer review

- Open access: articles freely available online

High visibility within the field

- Retaining the copyright to your article

Submit your next manuscript at $\boldsymbol{\nabla}$ springeropen.com 